\title{
El control público de las Cooperativas de Ahorro y Crédito
}

\author{
Alberto García Müller \\ Universidad de los Andes (Venezuela) \\ amuller@ula.ve
}

\section{Concepto de control público}

El control público consiste en la actividad de examen o de revisión que la autoridad pública realiza sobre una empresa, para verificar la conformidad de su actuación con el cuadro normativo dentro de la cual opera. Para Cracogna $(2002,3)$ es la acción que realiza el Estado a través de diferentes oficinas $u$ organismos para vigilar el cumplimiento de las disposiciones legales y reglamentarias por parte de las cooperativas, desde su constitución y hasta que finalice su liquidación, es decir, a lo largo de toda su existencia

\section{a) Objeto}

Garantizar el cumplimiento por parte de las cooperativas de las normas legales, asegurar la consistencia de su patrimonio colectivo, mejorar sus niveles de gestión, normalizar su administración y, o verificar el mantenimiento de la identidad del sector, lo que los italianos denominan, la finalidad mutualistica.

Lograr la exacta observancia de las normas legislativas, reglamentarias, estatutarias; la subsistencia de los requisitos exigidos para la concesión de los beneficios fiscales o de otra naturaleza; garantizar el regular funcionamiento contable y administrativo; el exacto cumplimiento técnico y el regular desarrollo de la actividad que el ente se propone cumplir; la consistencia patrimonial y el estado de los activos y pasivos; dar sugerencias y consejos a los administradores y a los empleados sobre el recto y eficaz funcionamiento del ente y socorrerlo con su asistencia (Dabormida, 1999: 173). 


\section{b) Naturaleza}

Las actividades de control no deberían tener carácter sancionatorio sino, mas bien directivo, tutelar y asistencial. Más precisamente, tener carácter preventivo, esto es, evitar que las entidades incurran en infracciones. En tal sentido, consideran Hernández y López $(2003,104)$ que la fiscalización que realiza el Estado debe orientarse como una medida preventiva no sólo sobre la estructura y formación de las cooperativas, sino más bien, la tutela se debe considerar sobre la actividad y el campo de acción en que se desarrolla dicho ente.

\section{c) Fuente}

El control especial del Estado en las sociedades cooperativas no existe per-se; ello es producto directo de la legislación. Esto es, la intervención estatal sobre las cooperativas resulta de la facultad concedida al Poder Público de fiscalizarlas y controlarlas. Y sin el poder fiscalizador y controlador, el Poder Público no intervendría en las cooperativas, simplemente porque no tendría conocimiento de lo que estaría ocurriendo en su administración (De Campos, 1988, 88). De manera que el control administrativo sobre las cooperativas sólo se justificaría sobre aquellas entidades que operan en sectores de actividad protegidas por el Estado, y sólo por causales taxativas establecidas expresamente en la ley;

\section{d) Ambito}

Debe decidirse si se supervisan todas las cooperativas o tan sólo las que necesita más que un control normativo. Lo mismo, clasificar las cooperativas en categorías de intervención y supervisando más cuidadosamente las situadas en las categorías inferiores; limitar el período de estrecha supervisión a la fase inicial previa al registro o a los primeros años, o efectuar la supervisión estrecha como una actividad adscrita o reservada para los casos de urgencia y, de ser así, determinar quién debe decidir qué es una situación de urgencia.

El control puede ser igualitario, esto es, para todo tipo de cooperativa, o variable, según la eficacia de la gestión de la misma. Incluso, puede haber entidades exceptuadas, otras de control atenuado o intenso, según sus dimensiones o su tipo de actividad, etc. Se sostiene la necesidad de modificar el sistema de control, limitándolo solo a las cooperativas que gozan de beneficios fiscales, o eliminándolo del 
todo y sujetándolas a los controles previstos para los otros tipos de sociedad (Bonfante, 1999: 710).

Puede darse control sobre todas las cooperativas; sólo respecto de las instituciones financieras; o sólo sobre las empresas que no sean objeto, por diverso título y por su misma naturaleza particular, de otras formas de control de naturaleza pública (financieras, de seguros, etc). Puede ser de acuerdo a la importancia económica o social de la cooperativa, por ejemplo, las que sobrepasen determinado capital o volumen de operaciones, o cierto número de socios. Las consideradas como de «importancia», tomando en cuenta el tamaño y volumen de las operaciones económicas que realizan las cooperativas cotidianamente (Comisión, 2004: 32).

Por ello, el legislador debería definir los poderes de intervención del gobierno en la ley y debería reglar bajo qué condiciones las sociedades cooperativas que han demostrado su capacidad de dirigir sus propios negocios, bajo la forma de una administración y control democrático, puedan ser exceptuadas del control gubernamental. Por ejemplo, la clasificación en categorías en atención a la eficacia de su gestión, al realizarse la auditoria anual. En ese caso el legislador puede prescribir diferentes formas de inspección y control, para cada una de esas categorías: Categoría A: muy bien; Categoría B: pasable; Categoría C: en mal estado; Categoría D: a disolver (Münkner, 1988: 59).

Pero, además, es necesario encontrar un punto de equilibrio entre un control riguroso e inflexible en caso que la cooperativa inspeccionada se encuentre en una situación de continuas y graves irregularidades, y el rol de consultor en caso en que las irregularidades, no graves, provengan de una ignorancia excusable (Cotronei, 1998, 8)

\section{e) Sistemas}

El control público puede ser ordinario o especializado.

El ordinario es aquel al que se encuentra sometida toda empresa, de acuerdo a la legislación ordinaria. Implica tanto un normal control de policía sobre la actividad que desempeña la misma, como un control judicial sobre la regularidad del funcionamiento en la gestión de la entidad, comprendida la aplicación de sanciones. Esa intervención trata de impedir que todas las sociedades procedan de modo de frustrar la política gubernamental, destinada al bien público. En ella no hay la intromisión de agentes del poder público en las relaciones internas de la 
sociedad. Esa intervención se dirige apenas a los negocios practicados entre las sociedades y los compradores, usuarios o consumidores de sus servicios o mercancías, con la finalidad de evitar el abuso del poder económico, obedecer al control del abastecimiento o a la estabilización y o congelamiento de los precios (De Campos, 1988, 87).

En relación con control administrativo especializado para las cooperativas y entidades del Sector Social, hay tres principales corrientes:

1. Inexistencia de control: con base en el principio de la autonomía y el carácter de derecho privado que tienen las cooperativas, se plantea (sobre todo en Brasil a raíz de la constitución de 1988 que declaró la creación de cooperativas sin necesidad de autorización y prohibió la intervención del Estado en el funcionamiento de las cooperativas) que las cooperativas no pueden ser fiscalizadas, investigadas, asistidas en sus asambleas, tampoco están sujetas a solicitudes en relación a suspensión de decisiones internas, intervenciones, disoluciones, liquidaciones y control sobre sus actos por parte de las autoridades gubernamentales (Périus, 2001, 297);

2. Sin embargo, puede existir y es frecuente que exista un control administrativo adicional y especialmente establecido para las cooperativas, al que no están sometidas las demás personas jurídicas, salvo aquellas que manipulan valores que le son confiados por el público (Bancos y Seguros, fundamentalmente). Para algunos, esa intervención administrativa deriva de la naturaleza de utilidad social que se les reconoce a las mismas, a los beneficios fiscales que se les otorgan, y al sistema de preferencias reconocidas. Como sostienen Hernández y López $(2003,101)$ pese al origen de entidades de Derecho Privado de las cooperativas, se inició la costumbre de introducir en las normas jurídico-cooperativas, ciertas disposiciones dirigidas a legitimizar el control estatal de estas organizaciones. Afirman que ello forma parte del Derecho Natural Cooperativo.

De Campos $(1988,85,95)$ observa que en los países desarrollados esa intervención es menor que la ejercida en los países subdesarrollados, en donde la interferencia estatal es más acentuada, normalmente en lo que se refiere a las cooperativas, las que se hayan sometidas, muchas veces, a rígidos controles.

Por otra parte, generalmente la Administración Pública no tiene mecanismos apropiados de control que tiendan al perfeccionamiento de las empresas del Sector, sino que se trata de una acción vaga, distante, complaciente, sujeta a injerencias políticas y, por ello mismo, al- 
gunas veces facciosa y casi siempre inoperante, de los órganos administrativos, no obstante la seriedad y competencia funcional de algunos abnegados funcionarios.

Para Kesselman (1992, 104-105) el Estado solamente se halla legitimado a realizar un control amplio y permanente del funcionamiento regular de las cooperativas, en tanto y en cuanto desarrolla respecto de ellas, políticas de promoción, asistencia, fomento, etc. De no ser así, de considerarse a estas entidades un tipo societario más, aún respetando sus particularidades, su control no puede ni debe ir más allá del control de legalidad de su acto de constitución. Pero, además, el límite razonable a la injerencia del Estado está dado por el interés concreto y efectivo que éste manifieste y efectivice respecto del cooperativismo. "Por aquel principio que el interés constituye la medida de las acciones en derecho, una amplia acción de control sólo se justifica para hacer al sujeto pasivo de la misma titular de alguna ventaja».

3. Hay una opinión -minoritaria- que se manifiesta por el control estatal casi absoluto para garantizar que se constituyan sujetos autoorganizados e independientes, en pié de igualdad y capacidad legal suficiente ante los demás actores económicos y el propio Estado. En tal sentido, sostiene que la política regulatoria cooperativa debe basarse en una debida, clara y exhaustiva normativa -cuasi reglamentariade jerarquía suprema que fije el contenido y alcance de las relaciones de colaboración; delimite las acciones estatales de promoción, fomento, inspección, calificación, intervención y control (a priori y a posteriori) y su ejercicio; identifique la Autoridad de aplicación y sus facultades; determine los requisitos y limitaciones para reconocer y, en casos de sectores especialmente protegidos autorizar, la creación de cooperativas; infracciones, sanciones, procedimiento sancionador y de impugnaciones administrativas y judiciales ante actos estatales o administrativos; declare el régimen tributario especial, sus estímulos; y por último garantice que los futuros procesos regulatorios cooperativos, incidentalmente cooperativos o de otra naturaleza no minoren la opción cooperativa ni en lo económico ni en lo social. (Fernández, 2006: 17).

\section{f) Carácter}

Se sostiene que la supervisión debe ser un poder extraordinario de la administración. En efecto, un dispositivo gubernamental debidamente equipado para supervisar un número creciente de cooperativas resulta con frecuencia más caro que lo que el Estado puede sufragar. Sin una 
misión clara, sin personal calificado y motivado y sin todos los recursos necesarios, la supervisión estatal no será eficaz; y cuando incluso las cooperativas que pueden trabajar por si solas siguen siendo estrechamente supervisadas, la supervisión resulta contraproducente. Además, el rendimiento efectivo de una u otra forma sufrirá necesariamente, pues nadie puede inspirar confianza como asesor y actuar al mismo tiempo como inspector. La estrecha supervisión de todas las sociedades como actividad de rutina resta estímulo a la acción de autoayuda y tiende a perpetuar la supervisión. De ahí la importancia de hacer que ésta sea un poder extraordinario que se utiliza sólo cuando hay buenas razones para ello (Münkner, 1995: 15-16). Entonces, se puede concluir que la función de promoción es, indudablemente, incompatible con las funciones de supervisión y da lugar a una excesiva interferencia de los oficiales de gobierno en las cooperativas (Cracogna, 2002, 9).

\section{e) Control concurrente}

El control del sector puede ser ejercido exclusivamente por la autoridad administrativa o puede ser «concurrente» entre la autoridad gubernativa y la autoridad administrativa de la actividad y, o judicial, u otras autoridades. Ello se produce sobre todo en el sector financiero del Sector, en donde cada día se da más el control de las instituciones públicas de supervisión bancaria. Puede darse un control especializado para las operaciones y actividades propias del objeto social de las cooperativas, y otro, para las relaciones ente los socios y la Cooperativa y el funcionamiento de su aparato de administración interno (Naranjo, 1998: 25)

Ahora bien, el control entre los dos diversos tipos de vigilancia no podrá hacer que prevalecer, en el caso de la autoridad judicial, los intereses privados de los socios y sólo indirectamente el interés general y público, mientras que el control gubernamental estará dirigido prevalentemente a la tutela de los intereses públicos y sólo indirectamente a los privados de los socios (Cotronei, 2000: 17).

Por otro lado, el doble control por parte de la autoridad pública de la actividad productiva puede ser llevada, a causa de la profesionalidad específica a la que se dedique, a verificar el respeto sólo de la disciplina relativa a la empresa ejercida y no aquella relativa a la disciplina relativa a la particular organización que ejercita. Tal es el caso de vigilancia bancaria que busca la tutela exclusivamente de los intereses públicos de protección del ahorro, dejando de lado la promoción del cooperativismo de crédito y a la tutela de su identidad (Cusa, 2002, 35). 
Puede suceder - también- que el control concurrente sea asumido entre la autoridad nacional o federal, y las autoridades regionales o locales, bien sea por mandato expreso de la Ley, o por convenios celebrados al efecto. En tal virtud, la autoridad central establece los lineamientos generales y los parámetros dentro de los cuales se ejercerá el control, delegando en las autoridades locales su ejercicio práctico.

\section{f) Formas de ejercicio}

1. Inspección extra-situ o de control indirecto (analizar toda la información): evaluación económico-financiera: monitorear el comportamiento de las principales variables financieras: suficiencia de capital, calidad de activos, gestión administrativa, rentabilidad y liquidez; análisis de informes de auditorias externas; control patrimonial (reparto de utilidades, infracapitalización: revisión de actas, etc;

2. Inspección in-situ o de control directo: visitas a unidades; Constatación de hechos o actos; Asistencia a sesiones de órganos internos; Examen: documentación, libros, contabilidad; Ejecución: arqueos, supervisiones, revisiones, investigaciones; auditorias: contabilidad, administración, manejo técnico-social, consistencia patrimonial;

Ahora bien, como señala Pantano (2003: 18) sólo a través de la creación de un especial perfil profesional de inspector de cooperativas $y$, por tanto, de un cuerpo disgregado sobre el territorio, podrá ser realizada una vigilancia extraordinaria «creíble».

\section{g) Efectos}

Las funciones de control del Estado muchas veces conduce a que el mismo tenga un marcado carácter oficial y ello, a su vez, constituye un obstáculo mayor para una efectiva integración, y para su autonomía administrativa y financiera. Vive, en muchos casos, de favores del Estado. No llega a estructurar sus propias condiciones de sobrevivencia, advertidamente, porque vive en dependencia del Poder Público. Sin autonomía financiera y administrativa, el sistema no consigue consolidarse, crear sus propias reglas de protección y de regulación. Todo ello conduce a que no pueda caracterizarse como un sistema propio, independiente e integrado (Périus, 1988, 34-35).

El control público especializado, único o concurrente tiene como corolario que se de una creciente ingerencia estatal en la constitución y el funcionamiento de las cooperativas, lo que - a su vez - va producien- 
do una pérdida progresiva del sentido de autonomía (que es inherente a su propia naturaleza) la que no admite subordinación, lo que a su vez, lleva consigo la dependencia respecto de las agencias estatales.

Pero, a la vez, la «demasiada» ingerencia del gobierno en la organización, en la administración y en la disolución de las cooperativas; esa actitud «paternalista» genera a nivel de los asociados un compartimiento pasivo en relación con los deberes de controlar. En tal virtud, los socios, como dice (Périus, 1988, 56) en su buena fe, confían en la fiscalización oficial a tal punto que llegan a culpar al Poder Público de las liquidaciones de cooperativas, provenientes de mala administración. Justamente, es en la liquidación que se demuestra exactamente que, estructuralmente, el sistema fiscal que está practicado sobre distorsiones, visto que el órgano fiscalizador oficial nada pierde financieramente.

En tal sentido, en América Latina se considera que la supervisión estatal ha de reducirse a los límites estrictamente necesarios salvaguardando la autonomía de las cooperativas y permitiendo siempre recurrir a la justicia a fin de controlar los eventuales excesos de las autoridades gubernamentales. En este campo es importante permitir y fomentar el autocontrol a través de organizaciones del propio movimiento cooperativo (Comisión, 2005: 30)

En definitiva, la intervención del Estado debe ser subsidiaria, porque, en general, cualquier problema se debe tratar de resolver primero en la esfera interna del ente, tal vez con la colaboración o el control de la entidad de grado superior y, luego, recién entonces, con la intervención del órgano local competente o de la autoridad de aplicación, cuando corresponda (Moirano, 2005, 120).

\section{Instituciones que ejercen control sobre las Cooperativas de Ahorro y Crédito}

Es necesario distinguir cinco situaciones:

a) El control sobre todas las cooperativas de ahorro y crédito por medio de las agencias públicas de supervisión de entidades bancarias y financieras

En el Reino Unido, a partir del 2002 el control lo ejerce la Autoridad de Servicios Financieros del Estado. El Banco de España (Banco Central) junto a las autoridades especializadas en políticas financieras 
de las comunidades autónomas ejerce el control de las cooperativas de crédito y secciones de crédito. En las Canarias, la entidad pública financiera tiene poder de elaborar proyectos normativos, así como de inspección e instrucción de procedimientos sancionatorios. En Alemania existe un control de dos pisos: control formal (de calidad de gestión o desempeño cooperativo) realizado por las Federaciones de Auditoría — de afiliación obligatoria - autorizadas por el Estado. Las federaciones les hacen auditorías anuales o bianuales por medio de auditores especializados. Y control directo del Estado por parte de la Superintendencia de Servicios Financieros, sobre el acatamiento de la ley bancaria, así como supervisa el cumplimiento de las obligaciones de las federaciones. En Uruguay, la actividad de las Cooperativas de Ahorro y Crédito queda bajo el control de la autoridad bancaria. En Jamaica, desde 2002, las cooperativas de ahorro y crédito se someten al Banco Central. En América Central (salvo Panamá) prevalece el control por la autoridad de supervisión bancaria, asumiendo las federaciones labores de supervisión auxiliar.

\section{b) Control de las cooperativas de ahorro y crédito por autoridad especializada}

En los Estados Unidos de América, las «Credit Union» están controladas (exámen y revisión) por una Agencia especializada del Gobierno Federal, la National Credit Union Administration, dirigida por un Boureau compuesto por 3 miembros (especialistas financieros) designados por períodos de 6 años (prorrogales) por el Presidente de la Nación con la aprobación del Senado.

En Puerto Rico las cooperativas de ahorro y crédito están bajo la supervisión especializada de la Corporación de Seguros acciones y de Depósitos. Trinidad y Tobago tienen una autoridad especializada en cooperativas de ahorro y crédito la que actúa en conformidad con el Banco Central.

c) Control dual de las cooperativas de ahorro y crédito por la Autoridad de aplicación de las cooperativas y por las autoridades de supervisión bancaria

Barbados establece un control diferencial por grados, estando las de mayor grado supervisadas por el Banco Central y las menores por la autoridad administrativa. La República Argentina diferencia las Ca- 
jas de Crédito, supervisadas por la autoridad bancaria, de las mutuales y demás cooperativas que ejercen actividades diversas (incluidas las financieras) que están sujetas a un Instituto descentralizado y especializado de la Administración pública.

En Bolivia y Ecuador el control es diferencial de acuerdo a si las cooperativas operan sólo con sus propios asociados (cerradas) o pueden efectuar operaciones con el público (abiertas). Las primeras, son supervisadas por la autoridad de aplicación en materia cooperativa; las segundas, por la autoridad bancaria o financiera.

En Paraguay la supervisión de las Cooperativas de Ahorro y Crédito es ejercida por un Instituto especializado de la Administración Pública y los bancos cooperativos, por la autoridad de supervisión bancaria.

d) Control dual por parte de la Autoridad de Aplicación y las autoridades ordinarias

Italia, a partir de 2002, tiene una vigilancia ordinaria, ejercida en forma concurrente entre el Ministerio con competencia en la actividad y las federaciones nacionales, a efectos de garantizar el cumplimiento del principio de mutualidad. Y vigilancia extraordinaria, que es competencia exclusiva del Ministerio de la actividad. En Grecia, todas las cooperativas urbanas son supervisadas por el Ministerio de Economía Nacional, y las agrarias, por el Ministerio de Agricultura.

e) Control indiferenciado sobre todas las cooperativas por la autoridad de aplicación:

Chipre tiene un servicio de Auditoría dependiente del Ministerio de Comercio. En Japón, todas las cooperativas son supervisadas por la autoridad local (prefecturas). Bangladesh tiene un Departamento de Cooperativas que las registra y las supervisa en combinación con el Ministerio de Gobierno Local. En Tailandia, el control lo ejerce el Departamento de Promoción de Cooperativas. En Ghana, Mauricio y Kenya, el control de todas las cooperativas está a cargo del Registrador de cooperativas; en Senegal, le corresponde al Departamento de Agricultura.

Cuba, el control público se ejerce a través de los organismos de la Administración Central: los Ministerios; las estructuras provinciales y 
municipales y sus órganos de Control o Inspección, en razón de sus respectivas competencias. En República Dominicana, bajo el Instituto Especializado en materia cooperativa.

En Venezuela, el control de las cooperativas de ahorro y crédito los ejerce la Autoridad de Aplicación genérica en materia de cooperativas. Las cajas de ahorro (entidades semi-cooperativas de ahorro y crédito cerradas) son supervisadas por una Autoridad de Aplicación especializada en ellas.

Colombia ejerce el control de las cooperativas de ahorro y crédito por medio de una sección especializada (delegatura) de la autoridad de aplicación genérica para todo el sector solidario.

\section{El control único sobre todas las Cooperativas de Ahorro y Crédito por medio de la autoridad bancaria o financiera}

En esta materia al siguiente razonamiento se le da carácter de axioma: todas las cooperativas de ahorro y crédito deben estar sujetas al control de la autoridad única nacional en materia financiera o bancaria, y no por las autoridades que ejercen el control sobre todas las cooperativas.

Creemos que este argumento no se corresponde con la realidad por las siguientes razones:

a) Per-se, la supervisión ejercido por las autoridades bancarias no es eficiente, ya que el mero hecho de que sea ejercida por la autoridad bancaria no garantiza sus resultados. Nos parece que se trata de un falso supuesto, ya que la experiencia mundial arroja — de vez en cuando- colapsos bancarios puntuales de inmensas magnitudes, muchas veces con la connivencia de las autoridades de supervisión, cuando no con complicidad de las mismas. Además, nada obsta para que los mecanismos técnicos que se hayan comprobado eficientes en materia de entidades financieras, puedan serlo igualmente aplicados por autoridades especializadas en cooperativismo, pero adaptados a sus características específicas.

La experiencia de Puerto Rico y Colombia, entre otras, ha demostrado que la aplicación de los controles técnicos necesarios y suficientes por parte de autoridades no bancarias, arroja óptimos resultados sobre las cooperativas financieras. 
b) No es lógico aplicar a entidades de distinta naturaleza, los mismos criterios y mecanismos de supervisión, ya que sería colocar en un mismo plano a entes que son diferentes, con lo que se rompe el principio de igualdad. Por ello la autoridad de control y los mecanismos que emplee debe ser diferenciada, de acuerdo a la naturaleza del supervisado.

En efecto, las cooperativas (incluidas las de ahorro y crédito) tienen por finalidad la prestación de servicios preferente o exclusivamente a sus asociados, quienes son - al mismo tiempo- sus copropietarios; esto es, tienen la doble condición de usuarios y propietarios. En cambio, los bancos y demás entidades financieras tienen fines de lucro, es decir, obtención de beneficios económicos para sus dueños (que no son al mismo tiempo sus usuarios) por medio de la intermediación financiera.

c) La naturaleza de los actos que realizan los asociados con sus cooperativas de ahorro y crédito son diferentes de los que efectúan los clientes de los bancos. No son actos mercantiles, sino se trata de actos cooperativos, reconocidos en gran parte de las legislaciones latinoamericanas.

En efecto, los depósitos de dinero que hacen los asociados en sus cooperativas no son depósitos de ahorros; el dinero que la cooperativa entrega a sus asociados son actos de provisión de fondos propios (que no préstamos) y la remuneración de ese dinero no son intereses, sino remuneración por su uso (Torres, 1990, 212). Las operaciones no se regulan por la legislación bancaria sino por la norma cooperativa;

d) Las características mismas de las operaciones de las cooperativas de ahorro y crédito las diferencian sustancialmente de los bancos. Así, son de muy diverso tamaño, desde muy grandes a otras con pocos asociados; se trata de muy numerosas entidades, dispersas por todo el territorio; deben mantener agencias en zonas rurales apartadas o en localidades pobres de las ciudades; las cantidades de dinero que los asociados tienen generalmente son reducidas, lo mismo que el dinero que obtienen de sus cooperativas;

e) Como fue demostrado en otra ocasión en León, Guanajuato en 2004 (ver García Müller, A.) y como la experiencia de la Argentina así lo demostró, la supervisión por la autoridad bancaria sobre las cooperativas de ahorro y crédito les arrojaría daños irreparables, ocasionando la desaparición de las mismas como un sector diferenciado, o la 
pérdida de su identidad, como también ha sido demostrado acá en México.

\section{El control diferencial de las Cooperativas de Ahorro y Crédito según diversos criterios}

La doctrina especializada sobre la materia (ver referencias al final) sostiene que si no es posible ejercer la supervisión de todas las cooperativas de ahorro y crédito por parte de la autoridad bancaria, se debería ejercer un control dual, esto es: unas, por esa autoridad y otras, por la autoridad de control cooperativo, según diversos criterios:

a) Según que ejerzan operaciones sólo con sus asociados, o que sean autorizadas a operar con el público. Las primeras - cerradas- estarían bajo el control de la Autoridad Cooperativa; las segundas - abiertas - de la autoridad bancaria;

b) Según el grado de riesgo y el tipo de operaciones que realicen: las de bajo riesgo y limitadas a operaciones tradicionales, serían supervisadas por la autoridad cooperativa; las que efectúen operaciones riesgosas y «modernas» (tarjetas de crédito, manejo de remesas del exterior, operaciones en línea) por la autoridad bancaria;

c) Por el tamaño de la entidad, determinado por el número de asociados, el volumen de los depósitos de los miembros; el monto de los créditos, etc., de manera que las pequeñas estarían bajo la supervisión cooperativa, y las grandes, por la bancaria;

d) Lo mismo por el capital que manejan o del patrimonio de que disponen. De manera que según sea el monto del capital inicial, del capital mínimo o permanente, lo mismo que por otros indicadores de naturaleza financiera, las cooperativas serían clasificadas como de mayor o menor importancia en el mercado financiero, y controladas por agencias diferentes.

Sostenemos que todos estos criterios diferenciales no permiten discernir claramente entre entidades de naturaleza cooperativa, son imprecisos y hasta discriminatorios. Y lo que persiguen es que las cooperativas de ahorro y crédito "pequeñas» deban desaparecer por medio de fusiones imperativas, de manera de constituir cooperativas "grandes» que sean tratadas como bancos, las que al final de cuentas, sean convertidas en bancos. 


\section{Propuestas}

Con base a las consideraciones anteriores, nos atrevemos a sostener las siguientes propuestas:

a) Que la determinación sobre qué institución pública deba ejercer la supervisión de las cooperativas de ahorro y crédito sea producto no de criterios aproximativos de tamaño, riesgo, operaciones, capital, etc., sino del hecho que se trate realmente de una cooperativa, y no sea una simulación o una aproximación de cooperativa.

Para determinar si una empresa es o no cooperativa, el criterio debe ser si la misma cumple o no los principios cooperativos que es lo que - en definitiva - la caracteriza. Y ello se hace por medio de indicadores que miden el grado de cumplimiento de los principios cooperativos, a través del método del Balance Social Cooperativo, desarrollado por la Alianza Cooperativa Internacional junto con la Organización Internacional del Trabajo.

De manera que, sometiendo a la técnica del Balance Social Cooperativo a una cooperativa de ahorro y crédito, el resultado sería: si es auténtica cooperativa, queda bajo el control de la institución de control cooperativo; caso contrario, pasaría a la supervisión de la Autoridad financiera o bancaria.

b) Que el control público que se ejerza sobre las cooperativas de ahorro y crédito se lleve a cabo a través de una Institución que tenga las siguientes características:

1. Sea un Instituto, Corporación o Entidad de naturaleza pública;

2. Esté dotado de autonomía normativa, funcional, organizativa y administrativa;

3. Goce de personalidad jurídica y patrimonio propio;

4. Esté especializad exclusivamente en el control de todo el sector cooperativo y social, incluidas las cooperativas de ahorro y crédito;

5. Sus órganos directivos sean integrados por representantes del Estado y del propio sector cooperativo;

6. Sea dotado de adecuados recursos humanos profesionales de alto nivel de especialización y con independencia de criterio; de medios tecnológicos modernos, con especial utilización de la telemática; así como de recursos financieros apropiados y suficientes; 
7. Funcione de manera descentralizada, manteniendo a nivel nacional la definición de las normativas y políticas, dejando lo operativo a los niveles regionales y locales;

8. Su funcionamiento se adecue a las características propias del sector cooperativo, incorporándolo gradualmente en las labores de control;

9. Ejerza preferentemente una acción preventiva y de tutela, sin desmedro de la correctiva y sancionadora, cuando fuese necesario;

10. Haga hincapié en la aplicación de una verdadera cultura de control interno en todas las cooperativas y en especial, en las de ahorro y crédito;

11. La supervisión de las cooperativas de ahorro y crédito (así como la operatoria financiera de las secciones de ahorro y crédito de las cooperativas que realizan otras actividades) se ejerza por medio de una sección especializada del Instituto, que aplique técnicas de comprobada eficacia, procedentes o no de los mecanismos de supervisión de entidades financieras o bancarias y, porqué no?, en concertación con ellas;

12. De no ser legalmente posible la cobertura de las cooperativas de ahorro y crédito por parte de los sistemas estatales de garantías de depósitos, se provea la creación - a mediano plazo - de un organismo de integración que establezca un Fondo de Garantías de los depósitos de los asociados, de afiliación obligatoria, bajo sanción de retiro de la autorización para funcionar. Igualmente, la constitución de un Fondo de Estabilización Financiera que permita centralizar recursos excedentes y aprovisionar financieramente a cooperativas que lo requieran;

c) Una vez en el óptimo de su operatoria, se proceda al traspaso paulatino de las funciones del Instituto de Control Cooperativo al propio movimiento cooperativo a través de instancias especializadas desarrolladas por el mismo, de manera de llegar — a mediano plazo- al autocontrol cooperativo. Ello se podría hacer etapas que pasen primero por:

1. La figura del «colaborador técnico», entendido como el apoyo institucional que la entidad pública puede recibir para recopilar información, procesarla, y adecuarla por parte de organismos de integración, instituciones auxiliares o firmas especializadas. Tal labor de apoyo no tiene el carácter de supervisión delegada 
o de supervisión auxiliar, y se implementa en la medida en que se encuentren los mecanismos necesarios y las entidades idóneas para efectuarlo. El colaborador técnico debe cumplir con algunos requisitos mínimos de experiencia, infraestructura y legalidad; adicionalmente se requiere la conformación de un comité de supervisión que determine las responsabilidades, facultades, y prohibiciones en esta labor de apoyo;

2. La Supervisión auxiliar: efectuada por un una o varias federaciones o entidad privada independiente del sector. En tal caso, la autoridad pública es responsable, mantiene el poder de normativa y de sanción. Mantiene todas sus facultades, mantiene el control del auxiliar y/o alto grado de confianza en el mismo. Vela por la calidad de la supervisión del auxiliar. El auxiliar efectúa la Supervisión in situ. Raro que lo haga off site. Ejerce funciones instrumentales. Visita en el terreno. Se le delegan funciones de Supervisión. Requiere fuertes federaciones con alto grado de afiliación;

3. Supervisión delegada. La ley transfiere la supervisión en una entidad privada. Todas las funciones se trasladan al supervisor (on y off site). Incluye la facultad de intervención y de sanción. Crea la normatividad bajo la aprobación de la Superintendencia. La Superintendencia fiscaliza la federación. Es pagada por las cooperativas;

4. El autocontrol, en cuyo caso la Ley otorga o habilita a los organismos del Sector para ejercer el control sobre las entidades componentes del mismo, en régimen de plena autonomía decisoria, fijando las condiciones y el alcance de su ejercicio.

d) Crear un Instituto de Altos Estudios Cooperativos dedicado a la investigación autónoma sobre problemas que aquejan al sector; la formación en materia cooperativa de los recursos humanos de alto nivel necesarios para su desarrollo; centralización de la documentación pertinente y la prestación de asesoría especializada.

\section{Referencias}

ARZBACH, M. (2000). Regulación y Supervisión de cooperativas de ahorro y crédito en América Latin. Coopnetaldia, 0217, San José, DGRV.

ARZBACH, M. (2005). Organismos estatales para fomento y control de cooperativas en América Latina y el Caribe. Documento 13. Sao Paulo-San José, DGRV. 
Bonfante, G. (1999). Delle Imprese Cooperative. Art. 2511-254. Commentario del Codigo Civile Scialoja-Branca, Libro Quinto - Del Lavoro. Bologna, Zanichelli.

Comunidad Europea (2004). Comunicación de la Comisión Europea sobre el fomento de las cooperativas en Europa. $\operatorname{COM}(2003) 18$, Bruselas, Comunidad Europea.

Confederación Paraguaya de Cooperativas (2005). Hacia una supervisión del movimiento cooperativo paraguayo, Asunción.

Cotronel, G. (1998). «L' Ispettore di societa cooperativa, un ruolo difficile». Rivista della cooperazione 1/1998. Roma, Luzzatti.

Cracogna, D. (2002). Legal, Judicial and Administrative Provisions for successful cooperative development. Ulaanbaatar, ONU.

CRACOGNA, D. (2003). "La supervisión de las cooperativas en América Latina», Revista de Economía Pública, Social y Cooperativa, Valencia, Ciriec-España

CUSA, E. (2002). «La vigilanza sulla cooperativa nella legge N. 142, DEL 2001 ». Rivista della cooperazione 3/2002, Roma, Luzzati.

DABORMIDA, R. (1999). I controlli e la vigilanza sulle societa cooperative. Cooperative, consoprzi, reaggruppamenti, ipsoa.

De Campos, J. (1988). A Intervencao nas cooperativas. Inteferencia estatal nas cooperativas. Porto Alegre, Fabris.

Dupont, C. (2002). Modelo de supervisión para la delegatura de las organizaciones con actividad financiera, Bogotá, Supersolidaria.

España, ReINo de (1003). Ley de modificación de la Ley 18/2002, de 5 de julio, de cooperativas de Cataluña.

Fernández-Peiso, A. (2006). Neoliberalismo y derecho: una visión desde las cooperativas. Universidad de Cienfuegos, Cuba.

García-Müller, A.(2004). El daño que se hace a las cooperativas con un marco legal similar a los intermediarios financieros. México, Alcona.

HeRNÁNDEZ, O. y LÓPEZ, I. (2003). "Los sistemas de fiscalización y control en las cooperativas. Aplicación al caso de Costa Rica». Boletín de la Asociación Internacional de Derecho Cooperativo, 37. Bilbao, Universidad de Deusto.

IzURIETA, C. (s.f.). Marco legal para las cooperativas de ahorro y crédito en Ecuador, Quito.

Kesselman, S. (1992). «Estado, Autonomía y Autocontrol Cooperativo». Anales de las Jornadas Nacionales de Derecho Cooperativo, Buenos Aires, Intercoop.

MolRano, A. (2005). Manual de Cooperativas de Trabajo. Buenos Aires, Edunla. MÜNKNER, H. (1988). Principios Cooperativos y Derecho Cooperativo. Bonn, F.E.S.

MüNKNER, H. (1995). Examen de las repercusiones que ha tenido la recomendación sobre el papel de las cooperativas en el desarrollo económico y social de los países en desarrollo. Ginebra, OIT.

MÜNKNER, H. (2006). Intervención. Seminario Venezuela-Alemania sobre cooperativas, Caracas, UCV.

Naciones Unidas, Asamblea (1998). Papel de las cooperativas a la luz de las nuevas tendencias económicas y sociales. Informe del Secretario General, Nueva York, ONU. 
NARANJo, C. (1998). Visión general sobre el marco jurídico del cooperativismo ecuatoriano. San José, ACI-OIT.

Pantano, G. (2003). «La nuova vigilanza cooperativa e il ruolo dell'ispezione straordinaria». Rivista della cooperazione, 3/2003. Roma, Luzzati.

PerIUS, V. (1988). Atenacuao ou eliminacao estatal tendo en vista o projeto de autocontrole. A interferencia estatal nas cooperativas, Porto Alegre, Fabris.

Perius, V. (2001). Cooperativismo e Lei, Sao Leopldo, Unisinos.

Perú, RePÚBlicA, Ley General del Sistema Financiero y de Seguros y Orgánica de la Superintendencia de Banca y Seguros, 26702, Lima.

Puerto Rico, Estado Libre Asociado (2001). Ley de la Corporación Pública para la Supervisión y Seguro de Cooperativas de Puerto Rico.

SAINT-HILAIRE, S. (2005). ¿Porqué supervisar las cooperativas de ahorro y crédito?, Santo Domingo, Idecoop.

Sánchez, J. (2003). Supervisión: ¿sí o no? Síntesis 155. Lima, Fenacrep.

SUPERINTENDENCIA DE ECONOMÍA SOLIDARIA (s.f.), Bogotá.

TORRES Y TORRES, C. (1990). Derecho Cooperativo. La teoría del acto cooperativo. Lima, INESLA.

WiLlams, E. (2005). Algunos pensamientos sobre un nuevo régimen regulador para cooperativas de ahorro y crédito, St. Joseph, Eastern Credit Union. 